\title{
Fabrication and Qualification of Small Scale Irradiation Experiments in Support of the Accident Tolerant Fuels Program
}

Connor Woolum, Kip Archibald, Glenn Moore, Steven Galbraith

February 2016

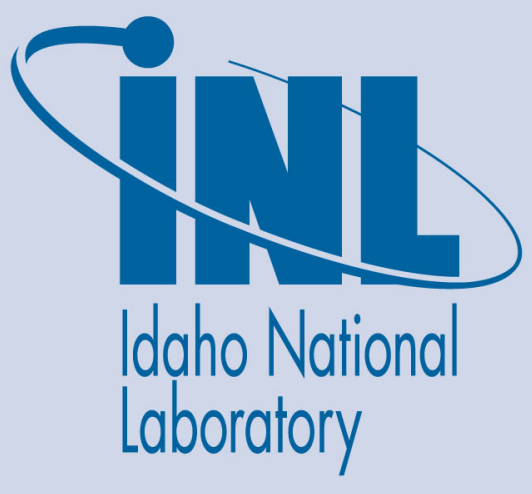

The INL is a U.S. Department of Energy National Laboratory operated by Battelle Energy Alliance 


\title{
Fabrication and Qualification of Small Scale Irradiation Experiments in Support of the Accident Tolerant Fuels Program
}

\author{
Connor Woolum, Kip Archibald, Glenn Moore, Steven Galbraith
}

February 2016

Idaho National Laboratory Idaho Falls, Idaho 83415

http://www.inl.gov

Prepared for the

U.S. Department of Energy

Under DOE Idaho Operations Office

Contract DE-AC07-05ID14517 

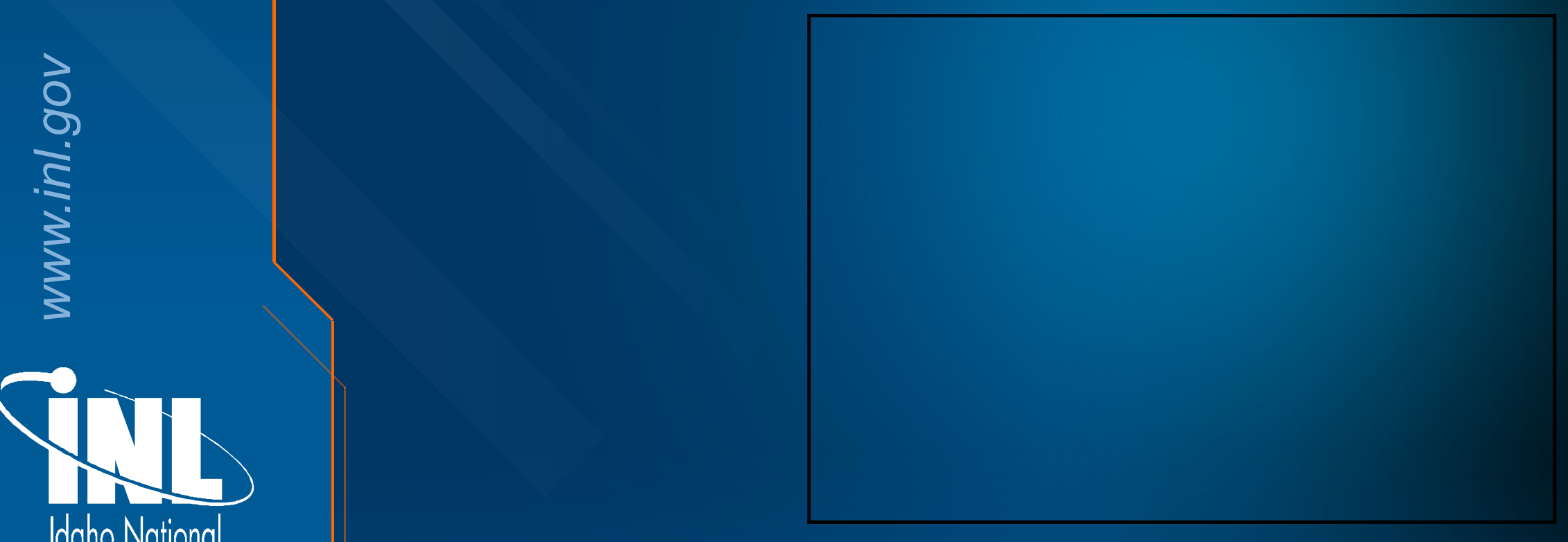

dadho National

Laboratory 


\section{Acknowledgements}

\begin{tabular}{cc}
\hline Name & Title \\
\hline Jon Carmack & FCRD National Technical Director \\
\hline Shannon Bragg-Sitton & FCRD Deputy National Technical Director \\
Heather Chichester & FCRD Irradiation Testing Technical Lead \\
\hline Steven Hayes & ATF Fuel Performance Principal Investigator \\
\hline Jason Harp & ATF Fuel Performance and PIE Principal Investigator \\
\hline Kristine Barrett & ATF Experiment Manager \\
\hline Brian Durtschi & Design Engineer \\
\hline James Reseigh & Quality Inspector \\
\hline Misti Lillo & Physics Analyst \\
\hline Christopher Glass & Physics Analyst \\
\hline Warren Jones & Thermal Analyst \\
\hline Stephen Evans & ATR Representative \\
\hline Michael David & ATR Experiment Engineer \\
\hline Christine White & Graphic Artist \\
\hline Steven Galbraith & FCRD Quality Engineer \\
\hline
\end{tabular}

The development of this paper was supported by the U.S. Department of Energy (DOE) Fuel Cycle Research and Development (FCRD) Advanced Fuels Campaign (AFC). This paper has been approved for conference presentation (INL/CON-15-35888). 


\section{ATF Overview}

- ATF Overview

- Fabrication

- Components

- Experiment Assembly

- Qualification/Validation

- Challenges

- Current and Future Activities

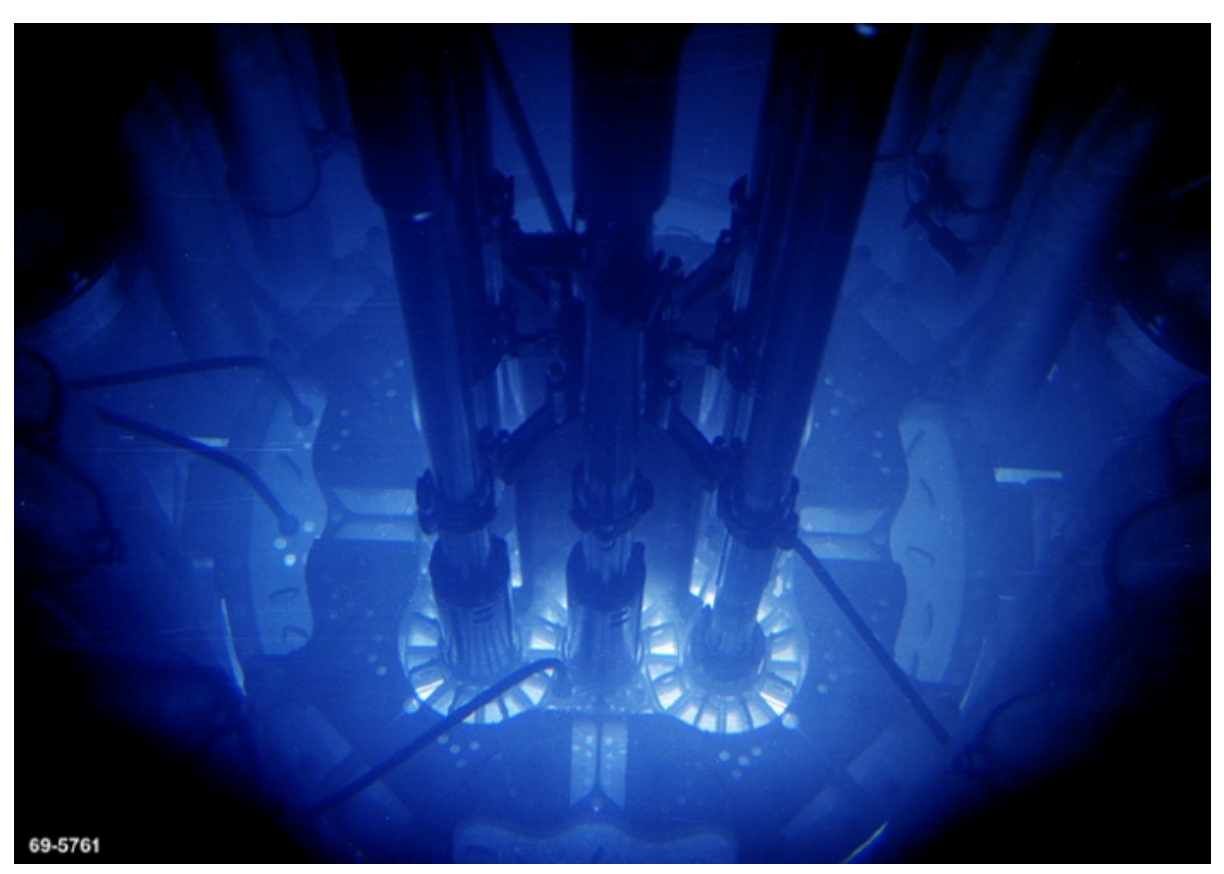




\section{ATF Introduction}

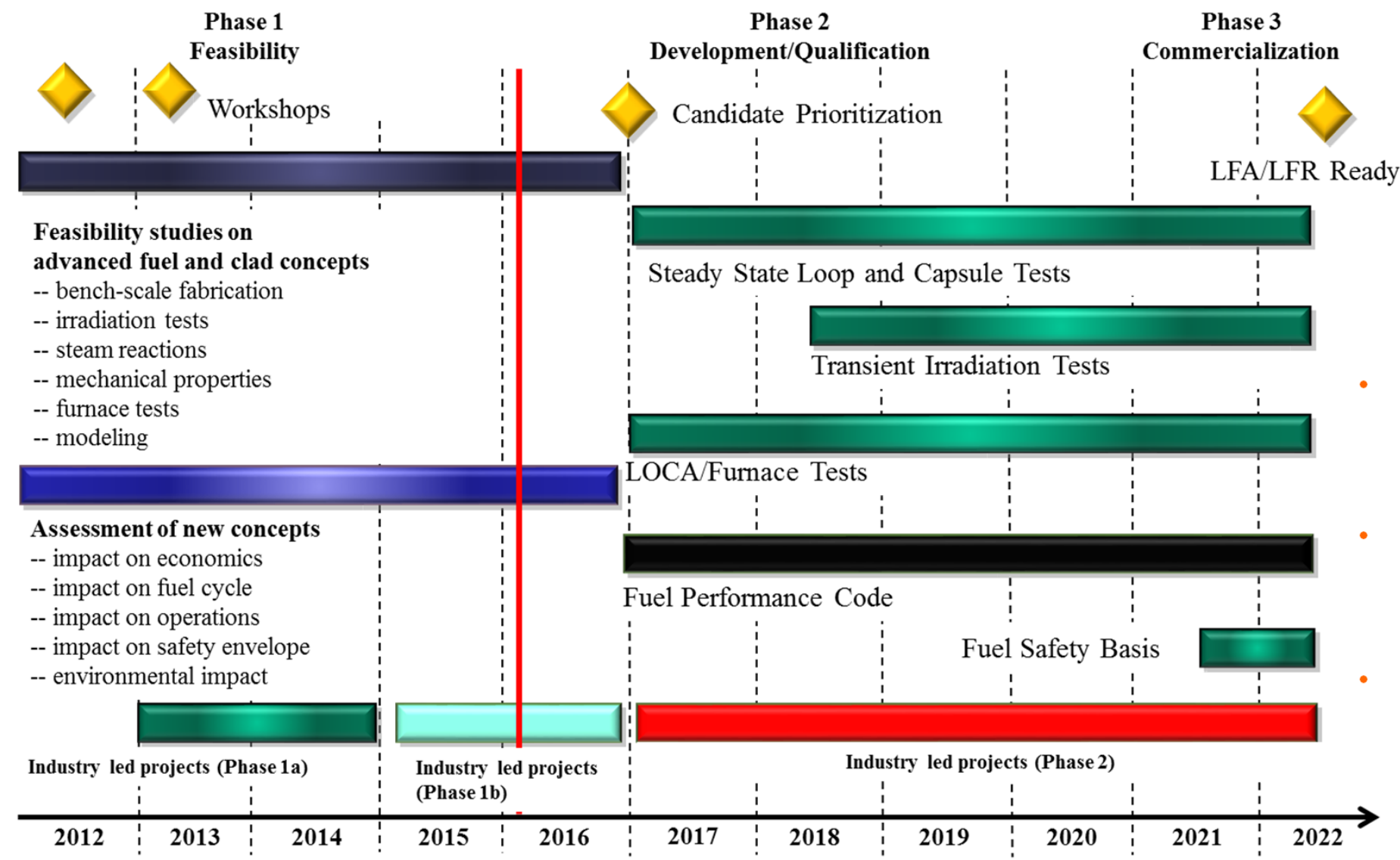

Accident Tolerant Fuels Goals Develop LWR fuels to improve the following during normal and accident conditions:

- Performance

- Reliability

- Safety

Innovative materials being tested must perform better than $\mathrm{UO}_{2}$ Zr system

ATR research will support

- Commercial reactor demonstration of LFA or LFR by 2022

ATR drop-in capsule experiments being tested as part of Phase 1 "proof of concept"

ATR loop test to be conducted as part of Phase 2

Currently in planning stages 


\section{ATF-1 Experimental Design}

- Small I positions in the ATR

- Experiment basket has 3 channels

- Each channel contains vertical stack of rodlets in capsules

(up to $7 \times 6$-in. capsules)

- Experiment safety limits

- LHGR $\leq 650 \mathrm{~W} / \mathrm{cm}$

- Capsule pressure $\leq$ 800 psi
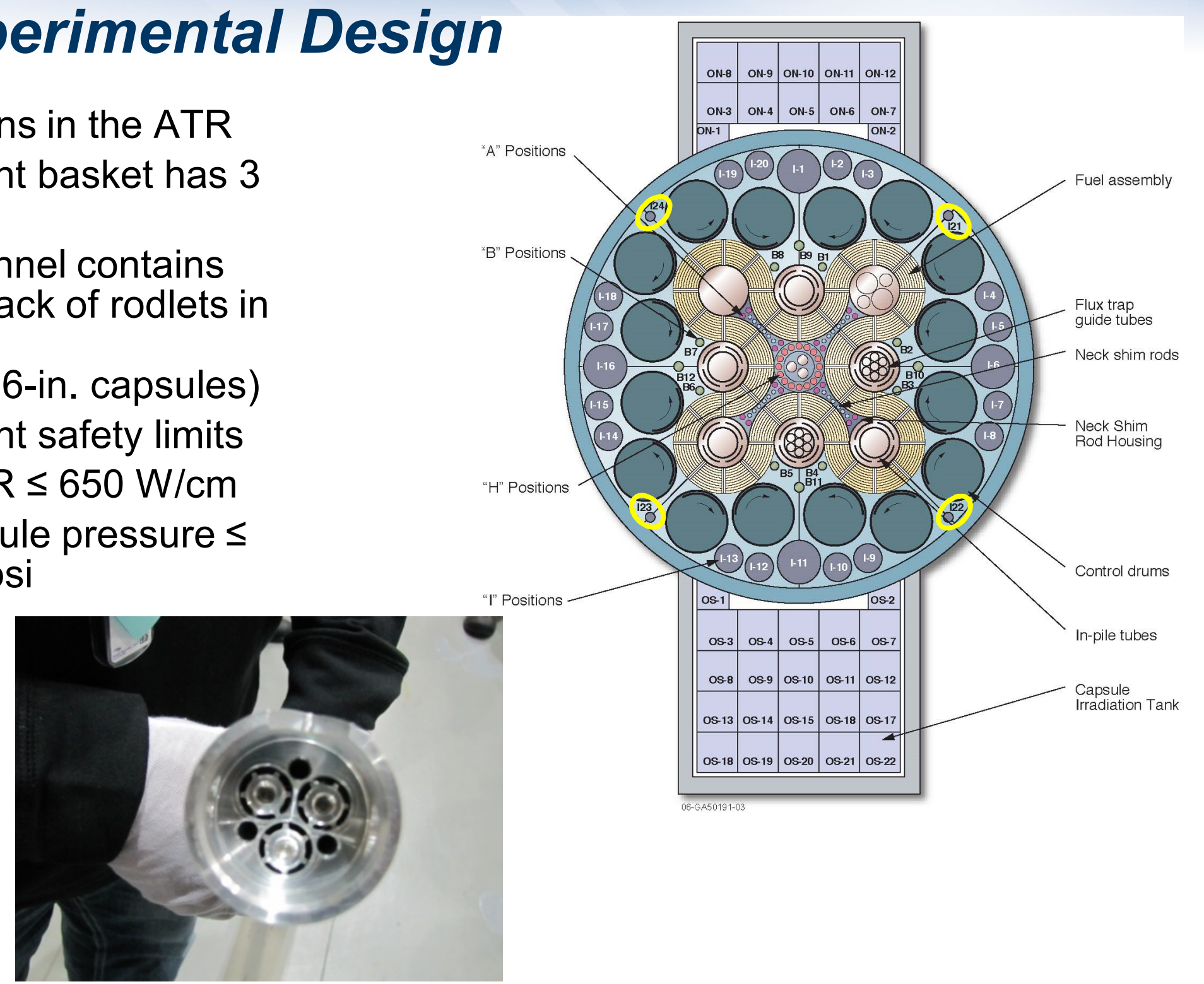


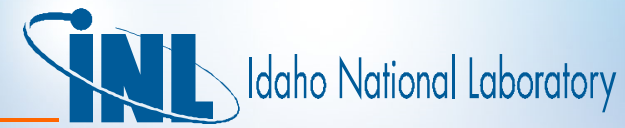

\section{ATF-1 Drop-In Capsule Design}

- Experimental fuels and cladding concepts

- Teams from industry, national labs, IRPs

\begin{tabular}{c|c|}
\hline Fuel Type & Cladding Type \\
\hline $\mathrm{U}_{3} \mathrm{Si}_{2}$ & Zirlo \\
\hline $\mathrm{UO}_{2}$ & Zircaloy-4 \\
\hline $\mathrm{UO}_{2}+\mathrm{SiC}$ whiskers & Zircaloy-4 \\
\hline $\mathrm{UO}_{2}+$ diamond particles & Zircaloy-4 \\
\hline $\mathrm{UO}_{2}$ & APMT \\
\hline $\mathrm{UO}_{2}$ & Alloy 33 \\
\hline $\mathrm{UO}_{2}$ & FeCrAl \\
\hline
\end{tabular}

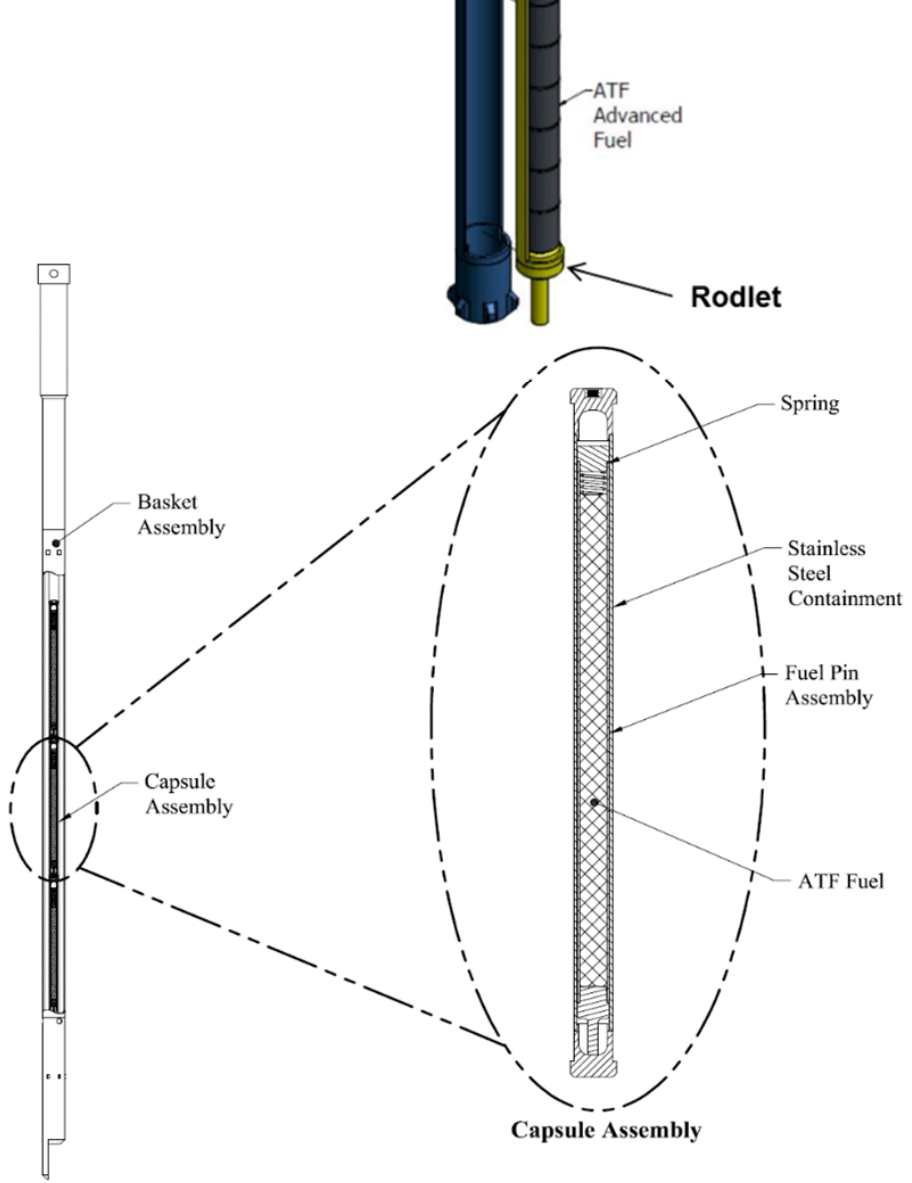




\section{Rodlet and Capsule Component Fabrication}

- Wire EDM

- Gun Drill

- Hone

- CNC Lathe

- Laser Etch

- Inspections
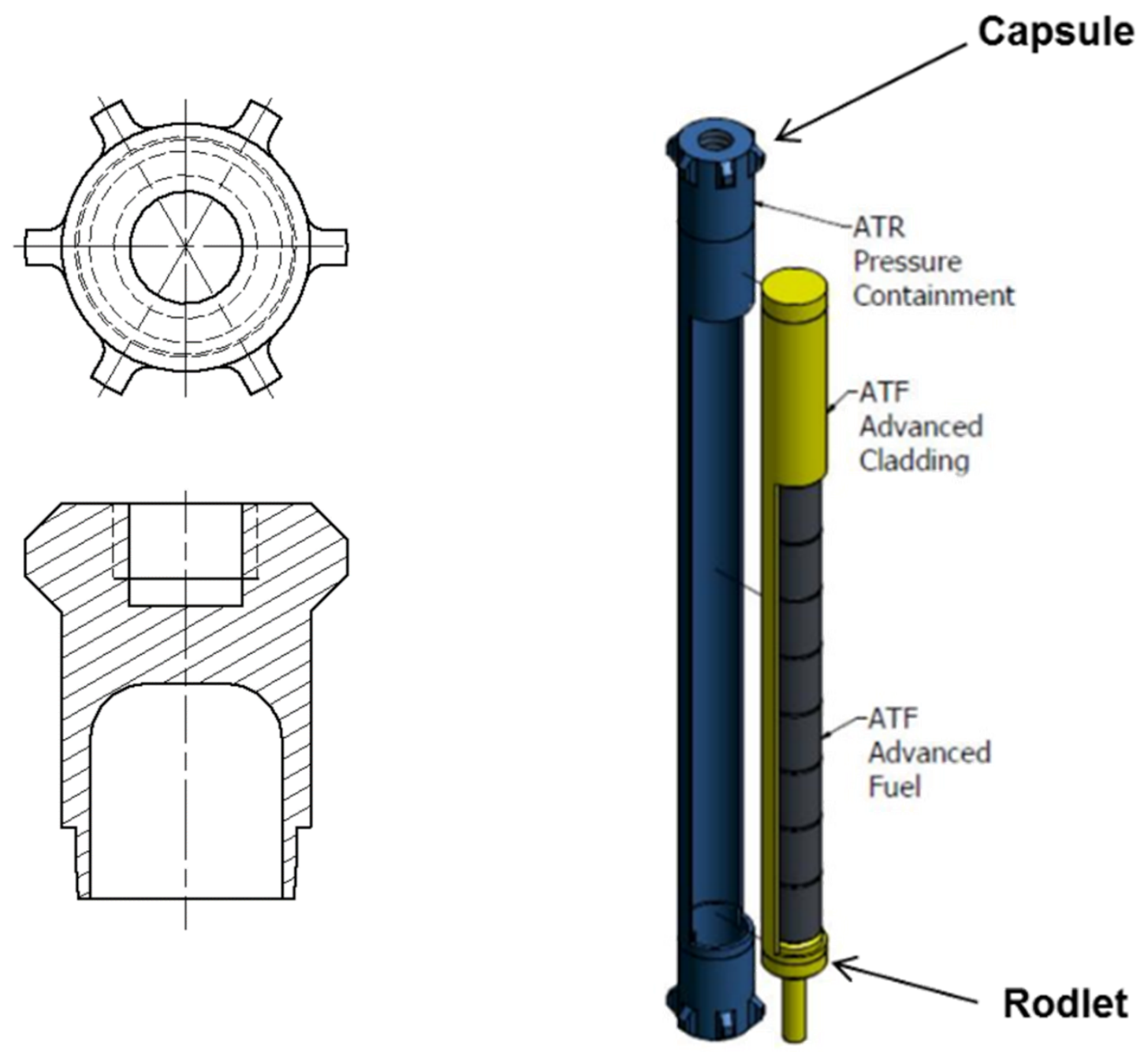


\section{Component Fabrication}

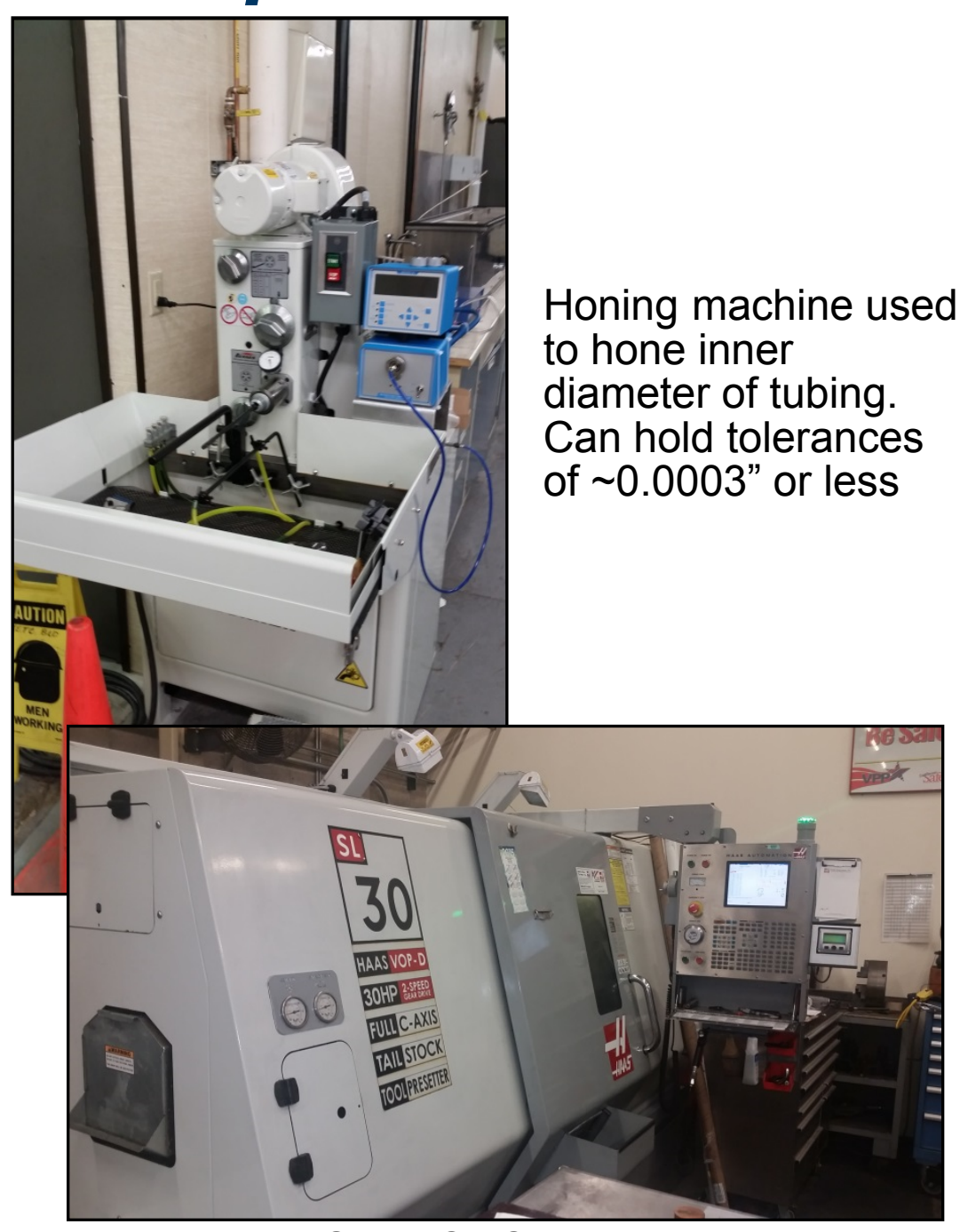

Haas SL30 CNC lathe used to

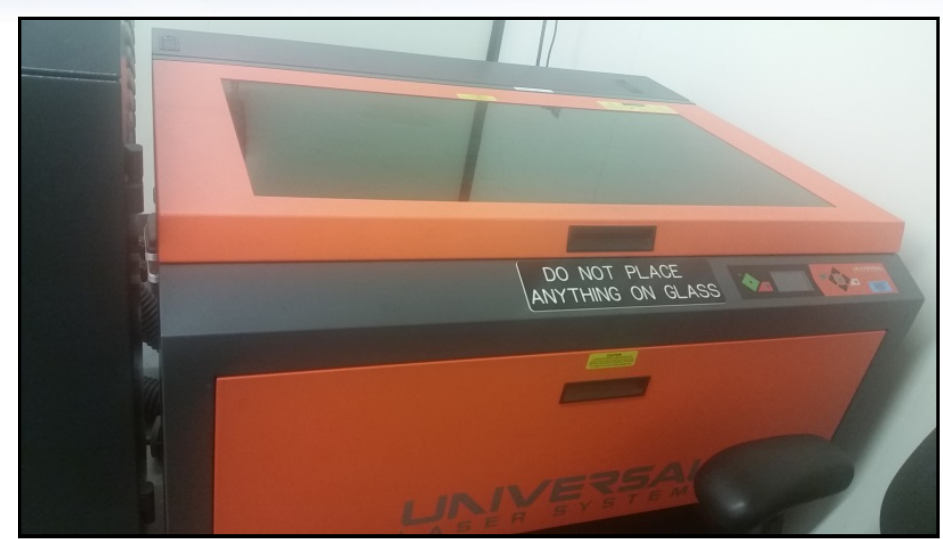

Laser engraving system to mark rodlet and capsule components

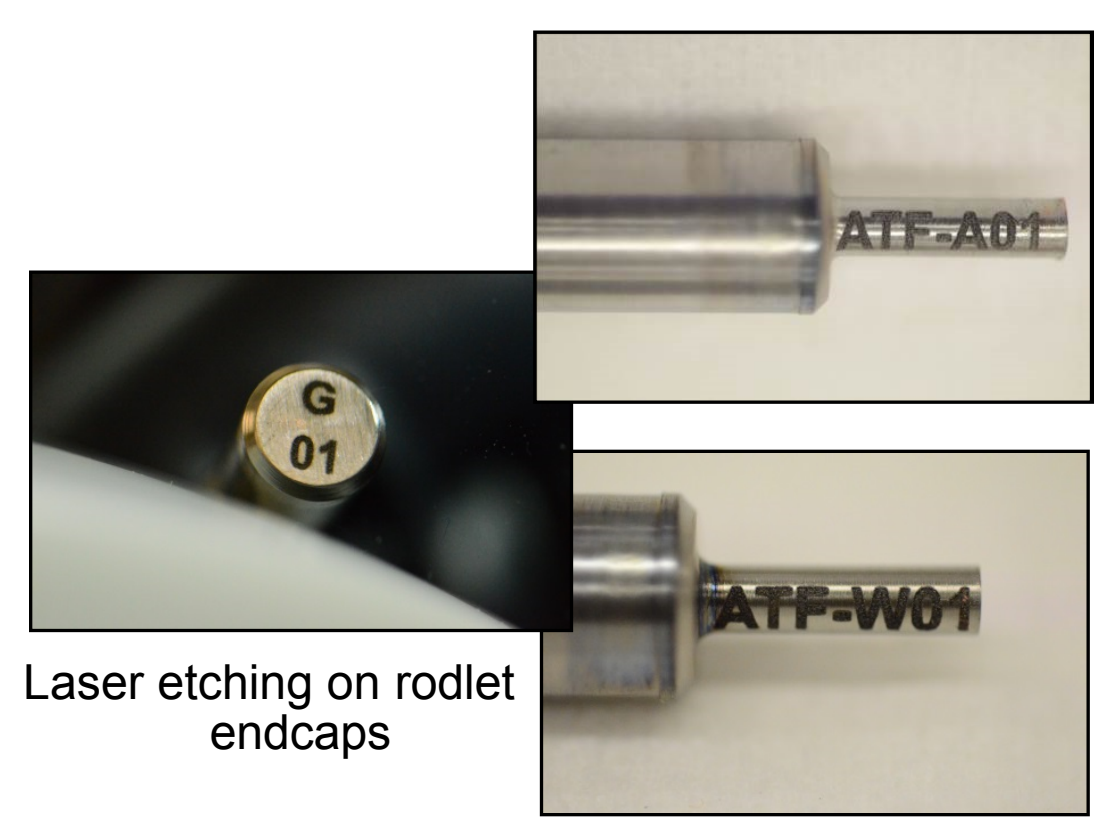
machine rodlet/capsule components 


\section{Inspections}
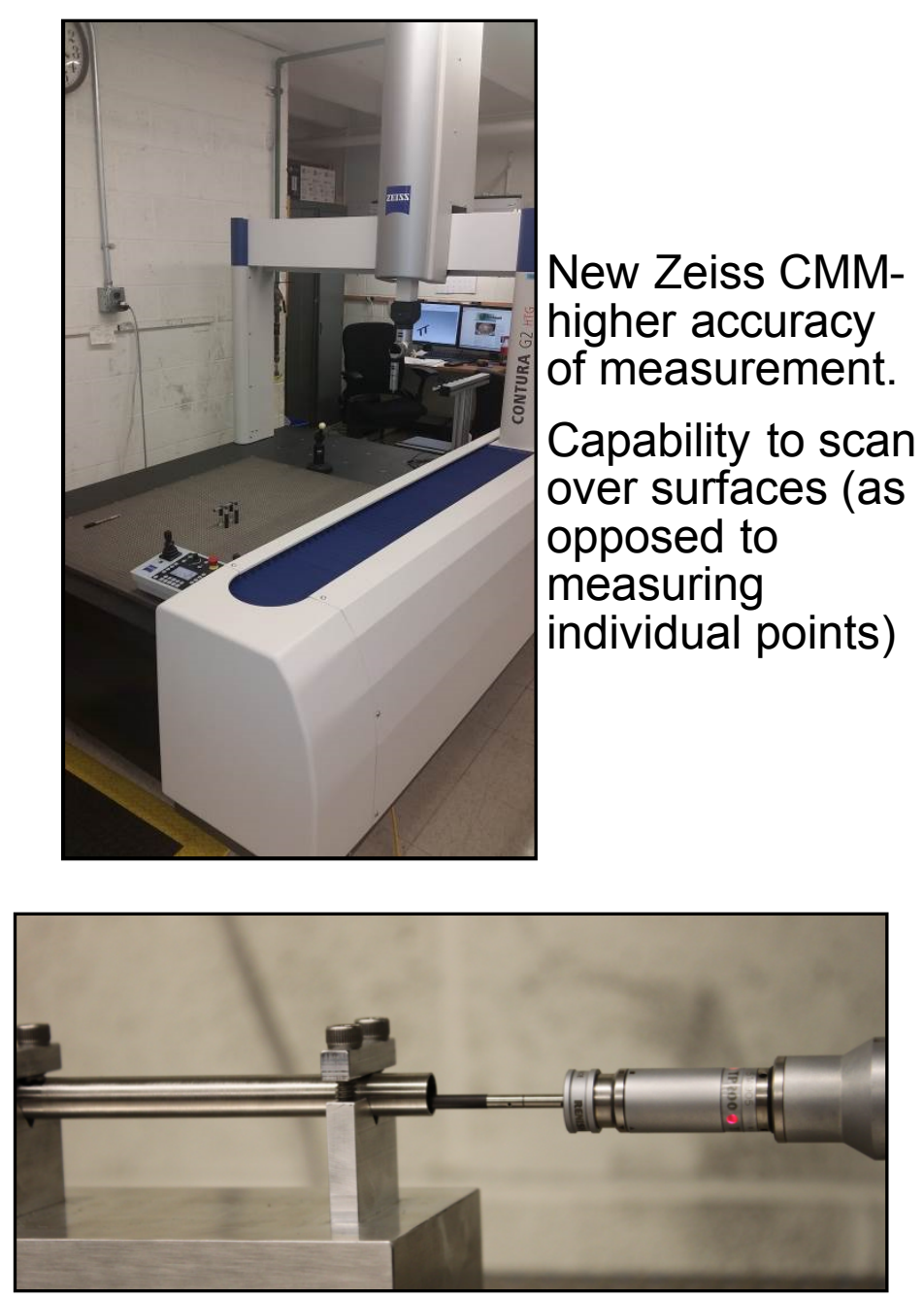

Wall thickness determined via ID and OD measurement points

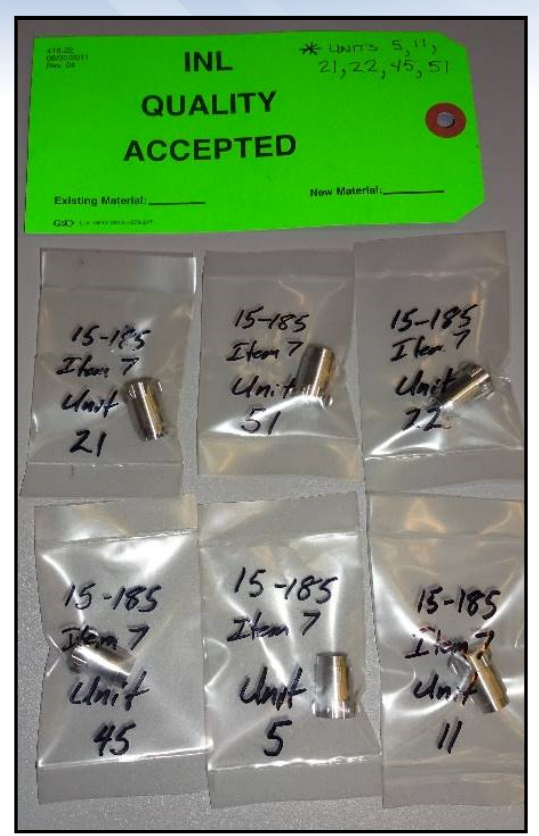

Left: Fully inspected capsule endcaps with quality status indicator ("green tag")

Below: Fueled rodlet assembly on CMM

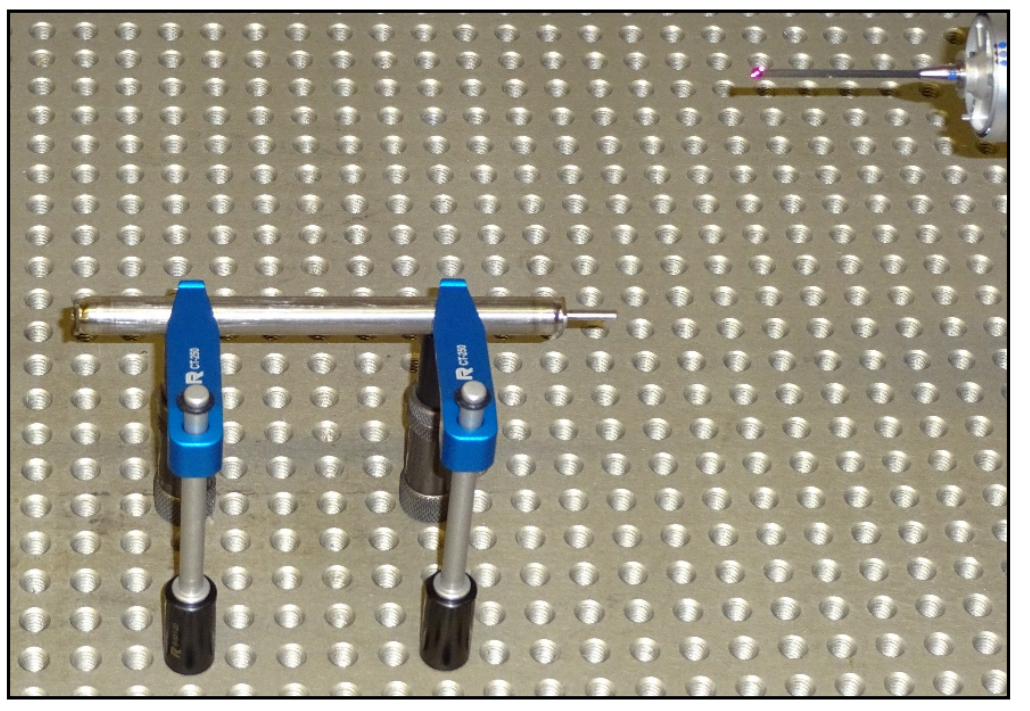




\section{Assembly/Inspection}

- Experiment Assembly

- Loading

- Welding

- Machining

- Inspections

- Helium Leak Check

- Dye Penetrant testing

- Radiography

- Computed Radiography

- Digital Radiography

- Dimensional Inspection

- Coordinate Measuring Machine (CMM)

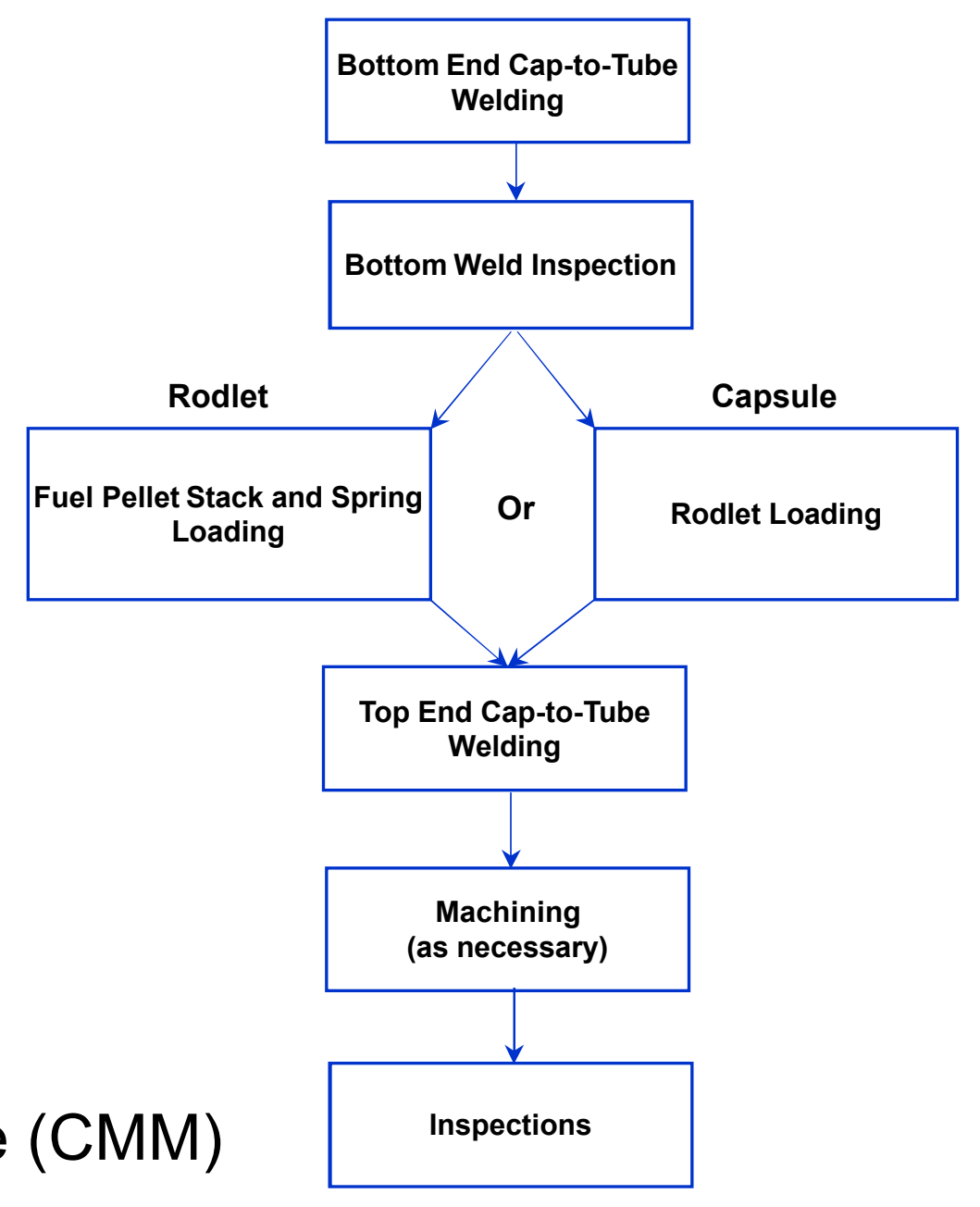




\section{Assembly}

- Arc Machines Inc. (AMI) orbital tube welding system

- Final assembly of rodlet and capsule assemblies

- Mbraun glovebox for inert atmosphere

- Assembled rodlets machined on Haas TL-1 lathe to fit into capsules

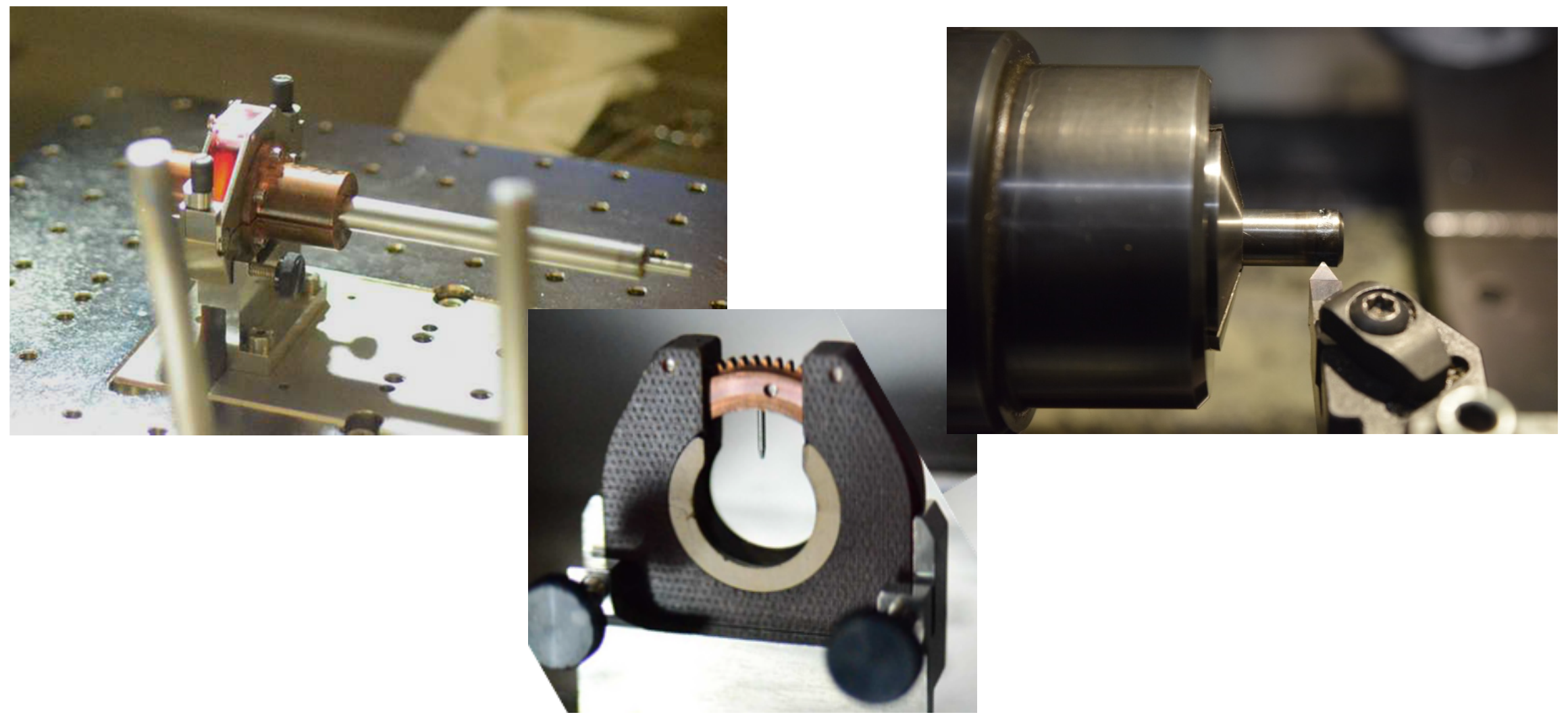




\section{Qualification}

- Radiography

- Computed radiography (CR)

- Welds

- Fuel/rodlet location

- Micro-focus digital radiography (DR) - $~ 5 x$ the resolution of CR system

- Evaluating CT system

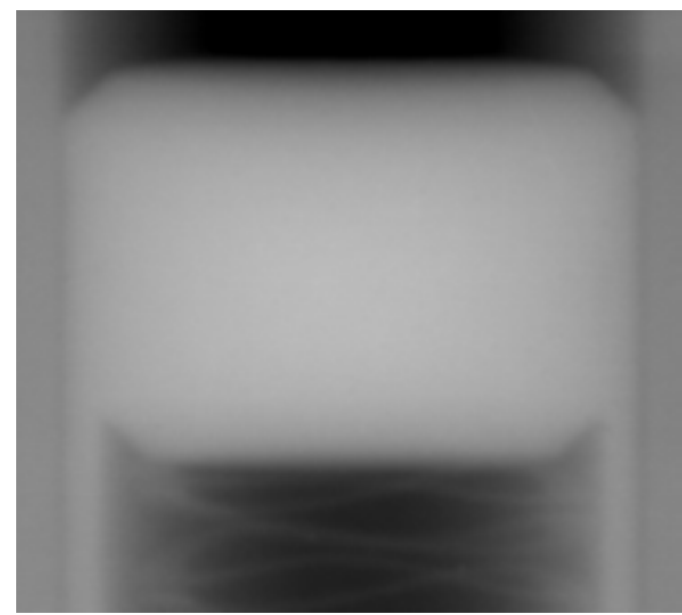

Left: Digital radiography of rodlet endcap

Below: Setup of digital radiography system

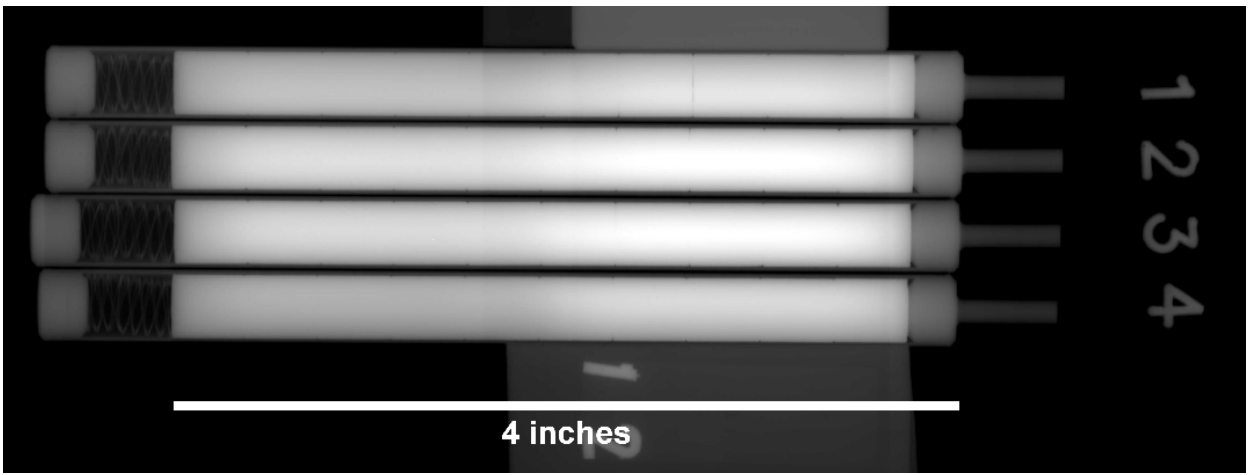

Fuel location radiograph of ATF rodlets (computed radiography)

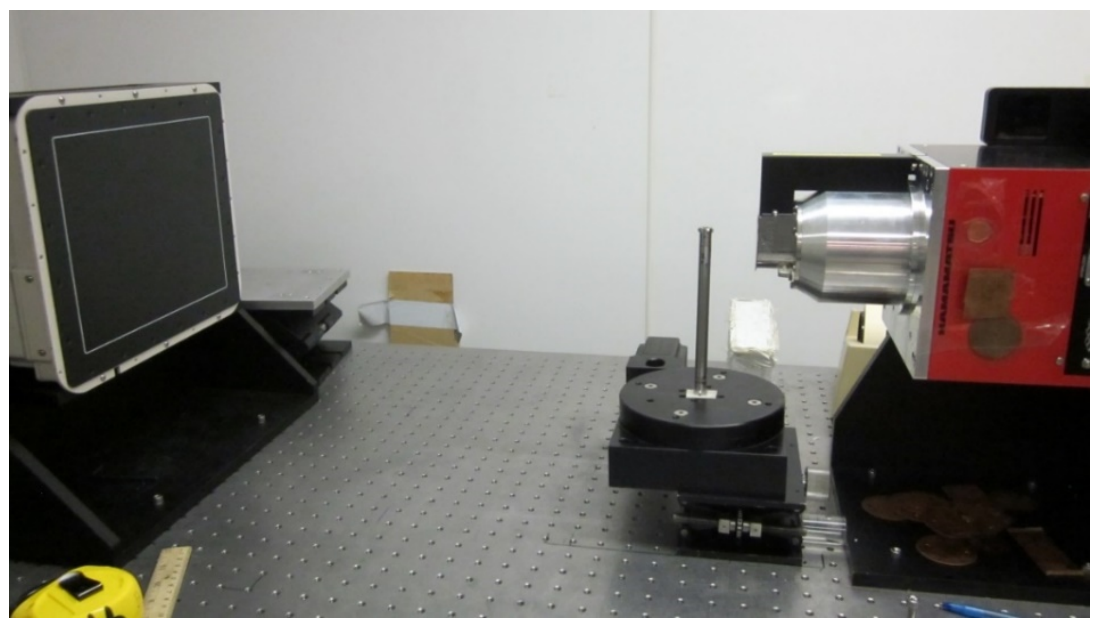




\section{Qualification}

- Metallography

- Etching

- Heat tinting

- Hydrostatic rupture tester installed for burst testing

- Validation of design and

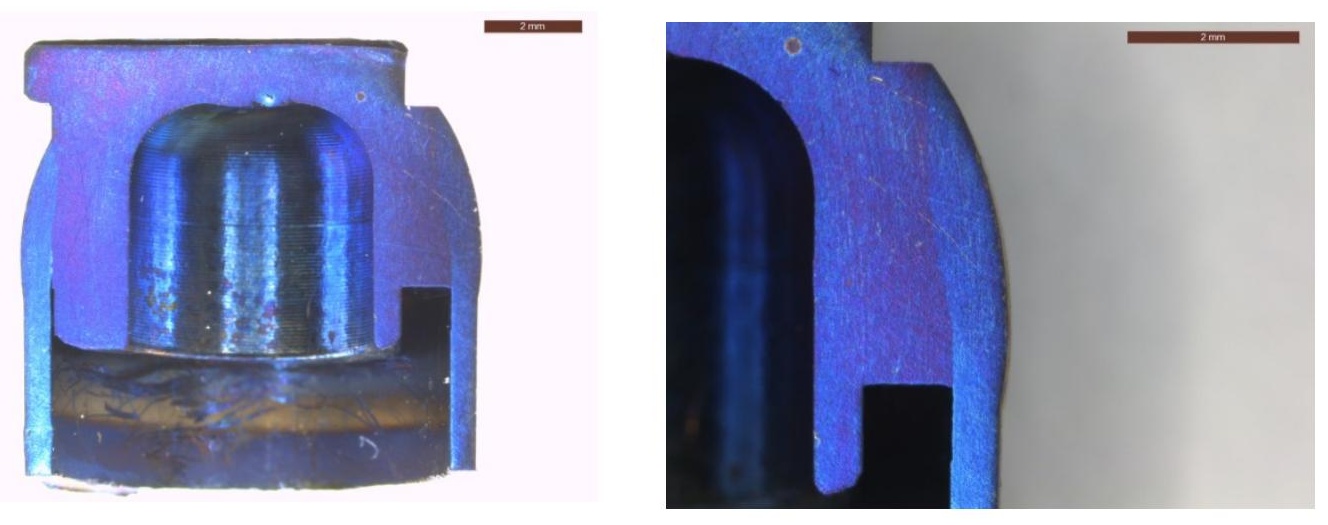
assembly parameters
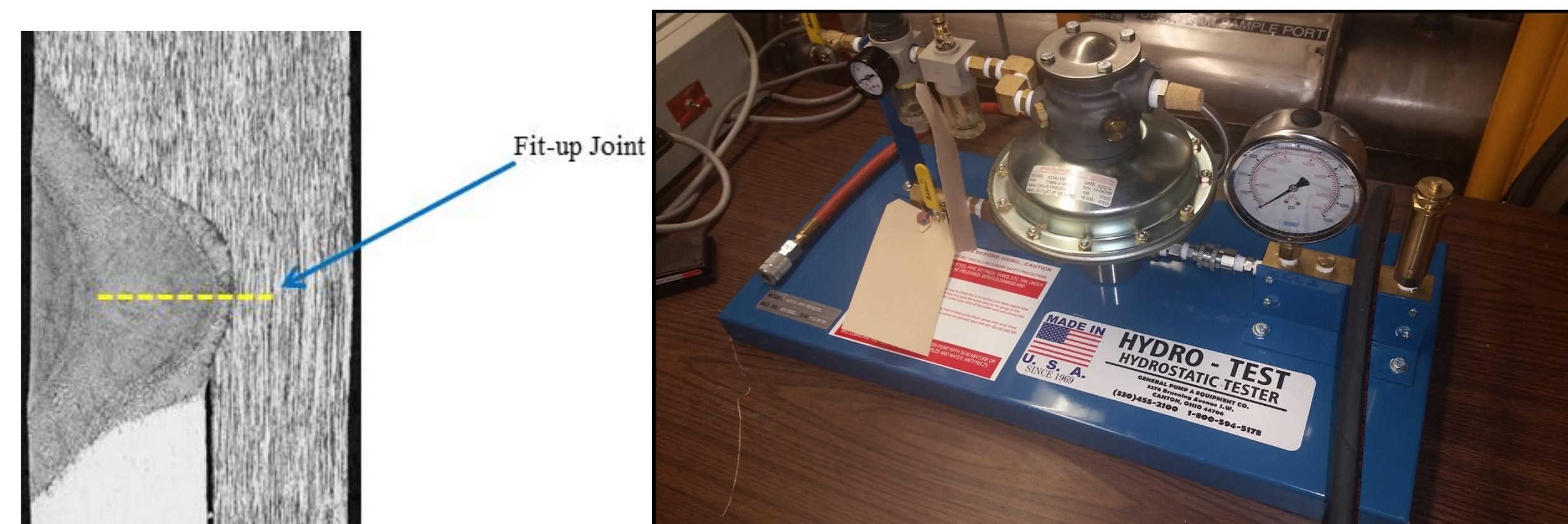


\section{Initial Issues}

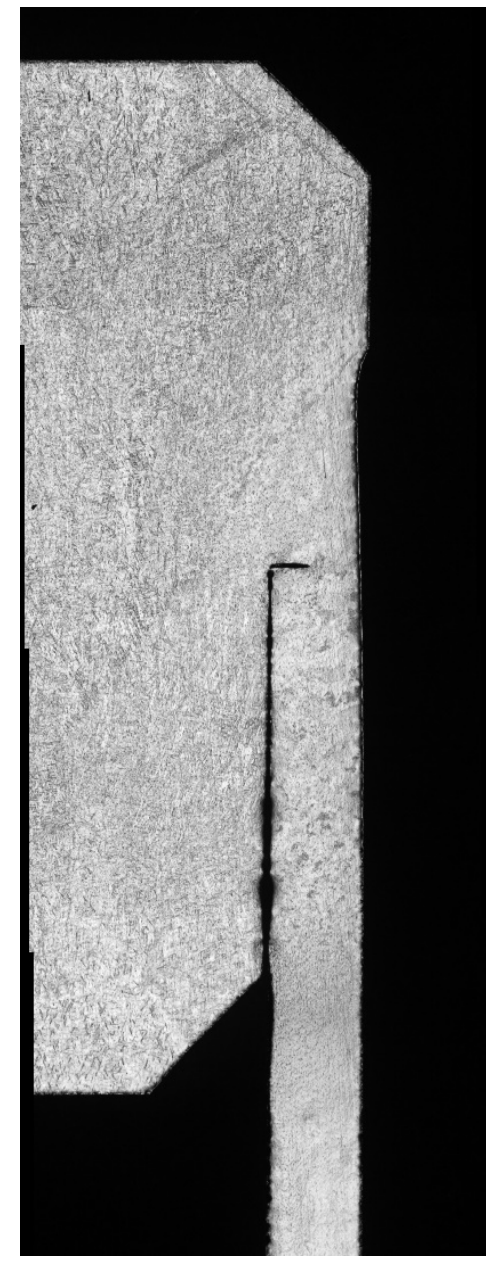

- Welding difficulties due to design and poor component fit-up necessitated process improvements:

- Tighter component tolerances

- Taper on rodlet endcap

- Adjusted cleaning requirements of components

- Alignment tools for tungsten positioning

- Additional copper chill blocks

- Successfully qualified 19 capsule assemblies for ATR insertion in initial ATF-1 campaigns 


\section{Design Change}

- Rodlet endcap design modified from solid plug to hollow design

- Addition of weep hole to mitigate gas expansion

- Required establishment of micro-TIG torch in glovebox for closure

- Different centering mechanism
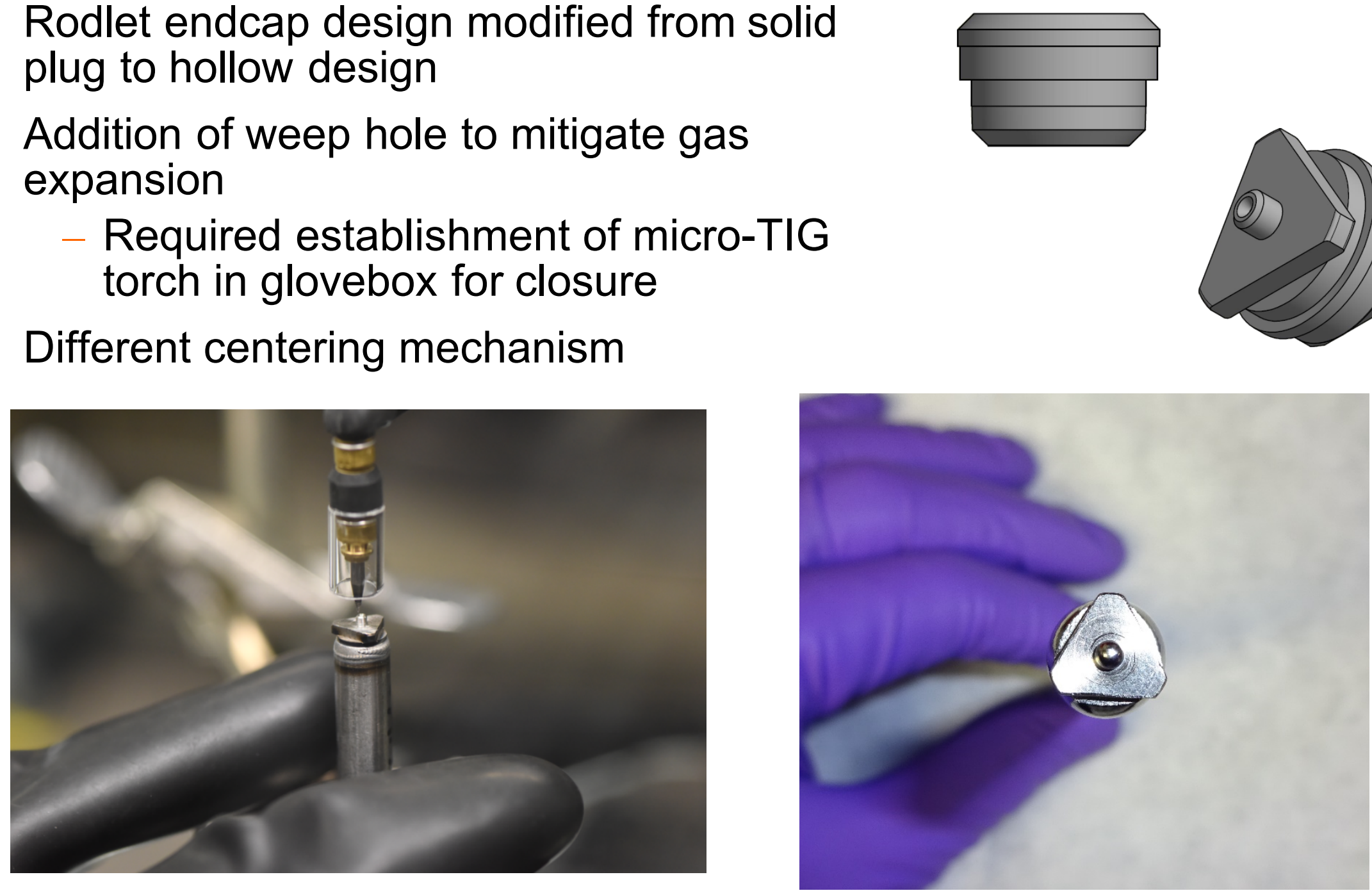


\section{Current}

- New issue with latest capsule welds

- May be attributed to sulfur content in new heat of SS316L capsule material

- Resolution is in-process and ongoing

- First experiments from ATF-1 campaign to be shipped for PIE later this month

- Additional fabrication campaigns within ATF-1

- AREVA

- Oak Ridge National Laboratory

- Los Alamos National Laboratory

- Evaluating additional assembly techniques

- Laser welding

- Pressure resistance welding 


\section{Future}

- ATF-2 is currently in the design and development stages

- Prototypical PWR conditions

- Loop test with instrumented fuel pins

- Live instrumentation in some of the pins for real time data collection

- LVDT's

- Temperature sensors

- Neutron detector

- Additional instrumentation for data collection between reactor cycles

- Many supporting efforts

- ATRC runs

- Autoclave test

- Sensor qualification test 


\section{ATF-2 Design}

- Modular test train assembly containing 5 tiers

- Each tier contains 6, 6" or 12" fuel pins

- Instrumented pins in top tier

- Remaining pins may contain LVDT's for measurements between cycles

- Also designed to allow for additional instrumentation after ATR irradiation, prior to transient testing

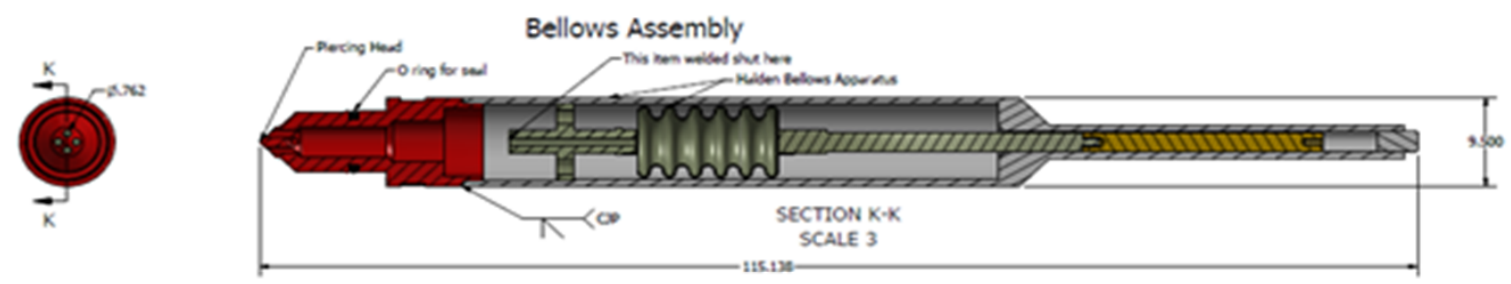

Bellows Assembly used to pierce irradiated fuel pins at TREAT

ATR fuel pin assembly 


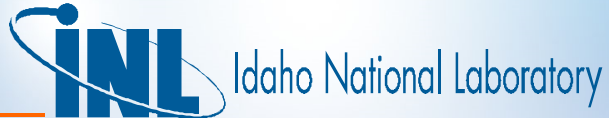

\section{ATF-2 Design}

甫
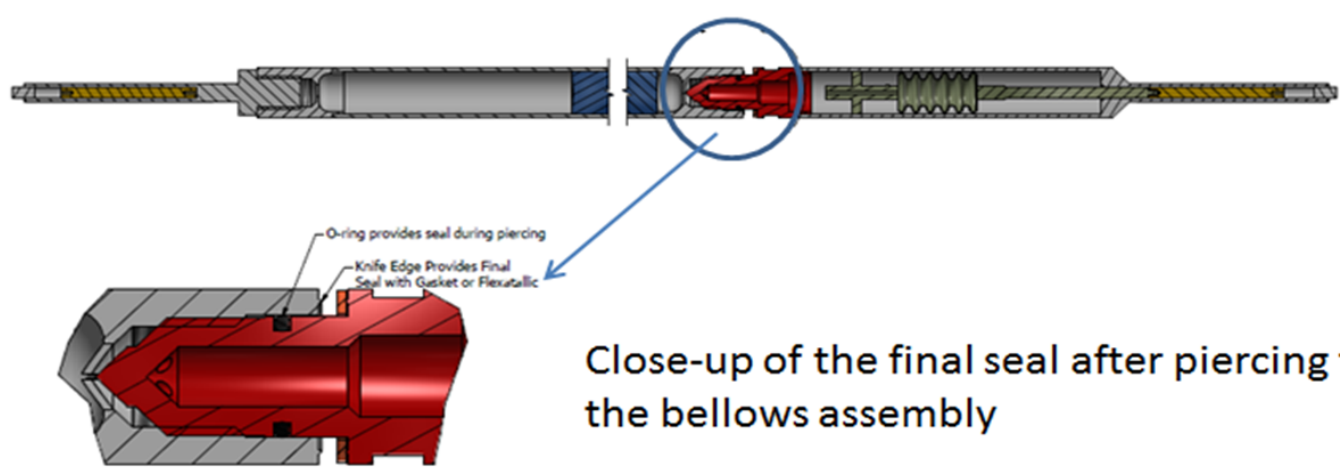

Close-up of the final seal after piercing fuel pin with the bellows assembly at TREAT
Pierced assembly

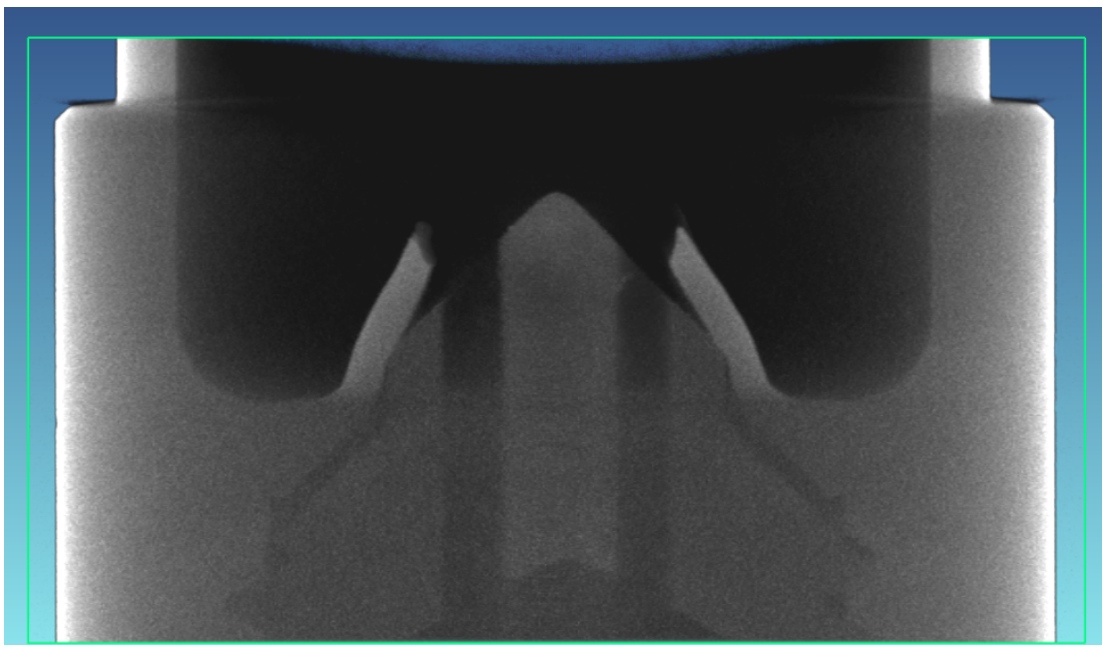

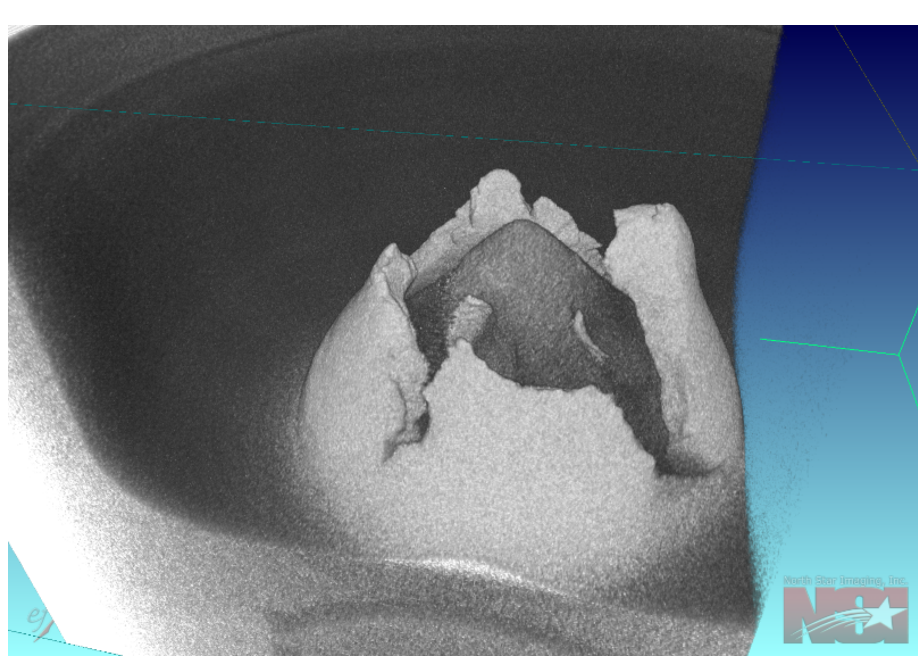




\section{Summary}

- Multiple successful fabrication campaigns

- First set of ATF-1 experiments scheduled for PIE this year

- New rodlet endcap design for improved fabrication success

- Established new capabilities to support fabrication

- Rupture testing

- Micro-TIG torch

- ATF-2 in the design and development stages

- Scheduled for ATR insertion in mid-2017 


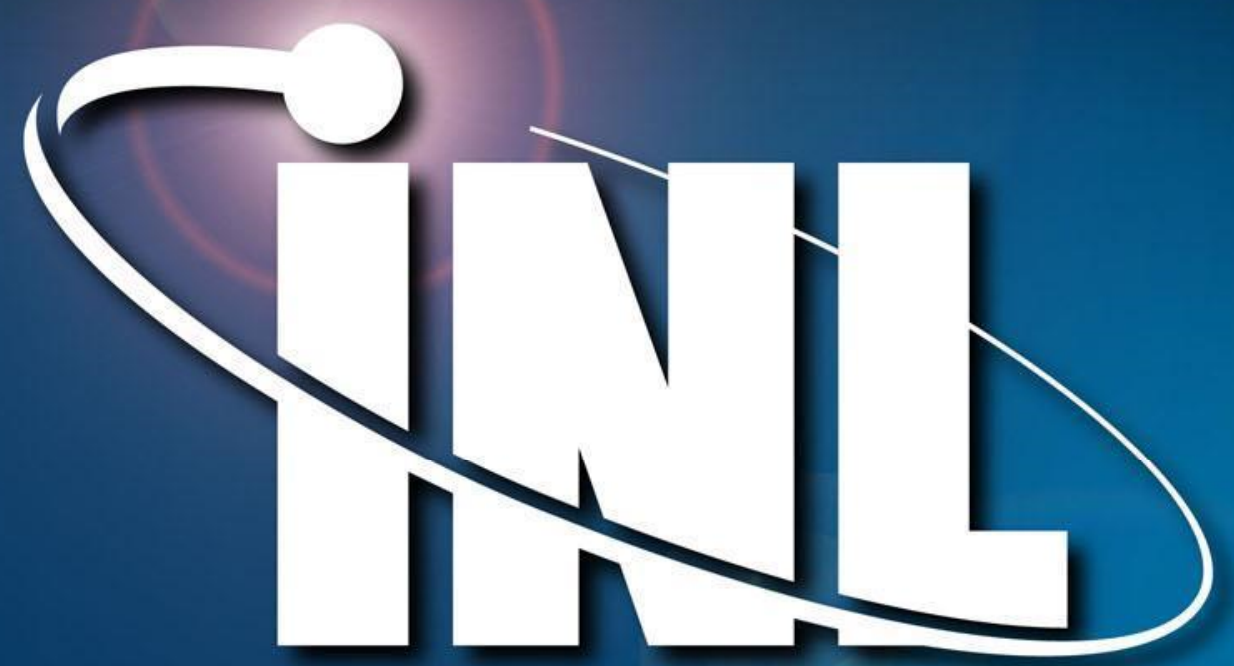

Idaho National Laboratory

The National Nuclear Laboratory 